\title{
CA125: Holy Grail or a Poisoned Chalice
}

See Bręborowicz et al., pp. c46-c51

\author{
Nicholas Topley Daryn Michael Timothy Bowen \\ Institute of Nephrology, Wales College of Medicine, Cardiff University, Cardiff, UK
}

Identifying easily measurable markers that are of prognostic value in predicting membrane failure in peritoneal dialysis (PD) patients remains one of the major challenges. Facilitating this endeavour has always been the ease of sampling of drained peritoneal effluent within which, with the development of ever more sensitive measurement techniques, any number of mediators can be quantitated. Local production of these 'factors' (i.e. of peritoneal membrane or infiltrating leucocyte origin) would then theoretically, at least, allow changes to be correlated with clinical outcomes and thereby their usefulness as indicators of altered membrane status. So far then there is an attractiveness and inescapable logic to this type of approach that would predict that after almost 20 years of investigation (since the first measurements of prostaglandins in peritoneal effluent $[1,2]$ ) there would now be sufficient data on a number of markers predictive of clinical and membrane-associated changes in these patients. Unfortunately, however, despite significant scientific endeavour (and as we will discuss a number of long-term clinical studies) we are really little nearer to identifying our holy grail.

\section{CA125: A Marker of Mesothelial Cell Mass in PD Patients?}

The history of (and perhaps the lessons to be learned from) peritoneal CA125 investigation presents no better example of the difficulties in assigning the status of a 'marker' predictive of membrane dysfunction to factors measured in dialysis effluent. In 1995, Visser et al. [3] were the first to suggest that CA125 could be used as 'a bulk marker of mesothelial cell mass in stable PD patients'. This was suggested based largely on in vitro and ex vivo approaches that suggested a mesothelial-cell-specific location (i.e. it is not expressed by leucocytes). Their data also suggested passive secretion of the antigen and a relationship to the number of mesothelial cells in culture. These data on the 'regulation' of secretion, however, were at odds with both pre-existing and subsequently produced data suggestive of induction of CA125 by pro-inflammatory cytokines [4, 5]. In the current issue, Bręborowicz et al. fan the flames of this debate further by suggesting, based exclusively on in vitro data, that CA125 production by peritoneal mesothelial cells neither correlates with, nor is regulated by pro-inflammatory cytokines [6].

The evidence ascribing CA125 as a clinical marker of mesothelial cell or membrane integrity was apparently strengthened by the studies of Ho-dac Panekeet et al. [7] who presented cross-sectional data suggesting a relation-

\section{KARGER \\ Fax +4161306 1234 E-Mail karger@karger.ch} www.karger.com (c) 2005 S. Karger AG, Basel $1660-2110 / 05 / 1002-0052 \$ 22.00 / 0$

Accessible online at: www.karger.com/nec
Prof. Nicholas Topley

Institute of Nephrology, Wales College of Medicine

Cardiff University, Heath Park

Cardiff, CF14 4XN (UK)

Tel. +44 29207 48432, Fax +44 29207 48470, E-Mail topley@cf.ac.uk 
ship between effluent CA125 levels and the time spent on PD. Again these data were highly contentious as Lai et al. [8] were unable to reproduce it in a study of similar size. At face value these apparently disparate findings would seem to cast serious doubt on the validity of CA125 as a marker of mesothelial cell mass or membrane integrity.

More recently, however, evidence for a beneficial relationship between CA125 levels and peritoneal 'health' has been reinforced based largely on studies comparing dialysis solution biocompatibility in short- to mediumterm randomised controlled clinical trials. In summary, continuous exposure of patients to solutions manufactured to be more biocompatible (e.g. neutral or physiological $\mathrm{pH}$ and reduced glucose degradation product levels) resulted in each of the studies in significant elevation of CA125 effluent levels that have been ascribed as evidence of increased mesothelial cell and membrane integrity [9-11]. Interestingly and yet unexplained, however, are the large differences in the magnitude of these changes in CA125 when comparing the different solutions in similar patient populations.

Clearly, there are a number of major difficulties with the 'CA125 hypothesis'. Principal among these is the fact that despite a significant and relatively recent increase in our understanding of its biology (see below), there are still far more questions than answers about what CA125 is doing in the peritoneal cavity and how its expression (both surface expression and secretion) are regulated.

\section{CA125: What Is It, How Is It Regulated and What Does It Do?}

Data produced largely over the past few years allow us to answer the first part of this question, to partly answer the second but unfortunately data relating to its function remain far less clear. Historically, CA125 was identified as an antigen reacting to the OC125 antibody in 1981 by Bast et al. [12] and is used clinically as the gold standard for monitoring ovarian neoplasms. Despite this its structure and function have remained largely unstudied until recently. The groups of O'Brien and Lloyd have produced much of the data relating to its molecular and genetic structure in the last few years [13-15]. It is now recognised that the CA125 molecule is a truly massive transmembrane glycoprotein consisting of multiple $(60+)$ repeat domains and an amino terminus. The extracellular portion is highly glycosylated [13].

The regulation of expression of such a vast extracellular structure is likely to be complex, while extensive work has shed little light on how its secretion is controlled. The most recent mRNA sequence available for CA125 (AF414442) exceeds $66 \mathrm{~kb}$ and resolves to 84 exons spanning over $130 \mathrm{~kb}$ of genomic DNA. This vast message encodes a theoretical product of 22,152 amino acids, although due to the highly iterative nature of the repeat region both nucleotide and translated amino acid sequences contain significant numbers of unknown residues.

The CA125 mRNA was first characterised as a 5.8-kb transcript [16] before $5^{\prime}$ additions extended the sequence to its present form $[13,14]$. Mindful of these successive recent expansions, we have analysed CA125 mRNA isolated from human peritoneal mesothelial cells using the 5 ' rapid amplification of cDNA end technology described recently in the identification of the transcription start site of the hyaluronan synthase 2 gene [17]. Our preliminary data have extended the CA125 sequence but suggest that further major additions are unlikely. How CA125 production is regulated at the mRNA level is unknown, and we are currently analysing the relevant upstream putative promoter sequences to identify elements involved in the regulation of its transcription [Michael et al., unpubl. data].

How CA125 is secreted is likewise still unclear, although its intracellular domain structure is suggestive of some signalling capacity, its size and the presence of a putative cleavage site suggest that proteolytic cleavage of the extracellular domains is the most likely scenario by which it is released. To date, however, neither the cleavage site, the size(s) of the released fragments, nor the enzyme(s) responsible for this have been identified [13].

\section{CA125: Where Are We Now?}

Therein lies the rub, whilst we know what it is, what it looks like and which cells express it, we have little idea of its biological significance. Although it is related genetically to the mucin (MUC) family (and in fact may indeed be encoded by the MUCIN 16 gene [15]), suggestive of a putative role in peritoneal lubrication, there is no clear evidence for this function.

One also has to ask the question whether comparing CA125 data based on in vitro and in vivo studies is really equivalent? If one does a simple calculation of appearance rates comparing published rates in patients (which are remarkably similar between studies) with those of Bręborowicz et al. [6] and other in vitro studies, then the rate of production in vitro is some 10-30 times 
higher. Whilst measurements in different matrices (tissue culture medium vs. effluent) might explain a small difference, there are clearly differences between a clean in vitro setup and the uremic peritoneal cavity exposed to both glucose-based dialysis solutions and intercurrent or episodic inflammation. Interestingly. Bręborowicz et al. [6] do show that chronic exposure of mesothelial cells to glucose specifically reduces mesothelial cell CA125 secretion and expression. Since glucose is the major osmotic agent used in PD fluids, this may in part help us to understand why its production in vivo is suppressed and that more biocompatible solutions increase its levels [9-11]. Given that more biocompatible solutions also contain equal amounts of glucose, however, the relationship to CA125 regulation is once again far from straightforward.

\section{Conclusions and Future Perspectives}

The debate will no doubt run and run, however until we properly define the regulation of CA125 at the molecular level, how and what controls its secretion/shedding and most importantly its biological significance/role, we will continue to be somewhat in the dark. The recent identification of its genetic structure provides a glimmer of hope as it now allows more defined studies on its molecular regulation and expression to be planned. Although not currently available, this information will likely pave the way for the generation of a CA125-deficient mouse (if viable) and the capacity to 'knock-down' its expression. Both of these approaches would doubtlessly provide benefit in understanding CA125 biology. With respect to its pre-eminent place as a marker of membrane integrity in $\mathrm{PD}$, the data are still far from convincing and certainly continue to polarise opinion. If CA125 is to be that holy grail that we seek then we will need to marry in vitro investigation of CA125 regulation with studies to define longitudinal changes in large cohorts of PD patients and controls. Once enough data are collected we will be able to analyse those clinical factors that impact on its production in the peritoneal cavity. If we fail to do this, CA125 will remain the enigma that it currently is and the search for the illusive marker of peritoneal membrane survival will go on and on.

\section{References}

1 Steinhauer HB, Günter B, Schollmeyer P: Stimulation of peritoneal synthesis of vasoactive prostaglandins during peritonitis in patients on continuous ambulatory peritoneal dialysis. Eur J Clin Invest 1985;15:1-5.

$\checkmark 2$ Steinhauer HB, Schollmeyer P: Prostaglandinmediated loss of proteins during peritonitis in continuous ambulatory peritoneal dialysis. Kidney Int 1986;29:584-590.

-3 Visser CE, Brouwer-Steenbergen JJE, Betjes $\mathrm{MGH}$, et al: Cancer antigen 125: A bulk marker for mesothelial cell mass in stable peritoneal dialysis patients. Nephrol Dial Transplant 1995; 10:64-69.

4 Zeillemaker AM, Verbrugh HA, Hoynck van Papendrecht AAGM, et al: CA 125 secretion by peritoneal mesothelial cells. J Clin Pathol 1994;47:263-265.

$\checkmark 5$ Zeimet AG, Offner FA, Marth C, et al: Modulation of CA-125 release by inflammatory cytokines in human peritoneal mesothelial and ovarian cancer cells. Anticancer Res 1997;17: 3129-3131
Bręborowicz A, Bręborowicz M, Pyda M, Polubinska A, Oreopoulos D: Limitations of CA125 as an index of peritoneal mesothelial cell mass - An in vitro study. Nephron Clin Pract 2005; 100:c46-c51.

7 Ho-dac-Pannekeet MM, Hiralall JK, Struijk DG, et al: Longitudinal follow-up of CA125 in peritoneal effluent. Kidney Int 1997;51:888893.

-8 Lai KN, Lai KB, Szeto CC, et al: Dialysate cell population and cancer antigen 125 in stable continuous ambulatory peritoneal dialysis patients: Their relationship with transport parameters. Am J Kidney Dis 1997;29:699705.

$>9$ Rippe B, Simonsen O, Heimburger O, et al: Long-term clinical effects of a peritoneal dialysis fluid with less glucose degradation products. Kidney Int 2001;59:348-357.

10 Jones S, Holmes CJ, Krediet RT, et al: Bicarbonate/lactate-based peritoneal dialysis solution increases cancer antigen 125 and decreases hyaluronic acid levels. Kidney Int 2001;59: 1529-1538.

11 Williams JD, Topley N, Craig KJ, et al: The Euro-Balance Trial: The effect of a new biocompatible peritoneal dialysis fluid (balance) on the peritoneal membrane. Kidney Int 2004; 66:408-418.
12 Bast RC Jr, Feeney M, Lazarus H, et al: Reactivity of a monoclonal antibody with human ovarian carcinoma. J Clin Invest 1981;68: 1331-1337.

13 O'Brien TJ, Beard JB, Underwood LJ, et al: The CA 125 gene: An extracellular superstructure dominated by repeat sequences. Tumor Biol 2001;22:348-366.

14 O'Brien TJ, Beard JB, Underwood LJ, et al: The CA 125 gene: A newly discovered extension of the glycosylated N-terminal domain doubles the size of this extracellular superstructure. Tumor Biol 2002;23:154-169.

15 Yin BW, Dnistrian A, Lloyd KO: Ovarian cancer antigen CA125 is encoded by the MUC16 mucin gene. Int J Cancer 2002;98:737-740.

16 Yin BW, Lloyd KO: Molecular cloning of the CA125 ovarian cancer antigen: Identification as a new mucin, MUC16. J Biol Chem 2001; 276:27371-27375.

17 Monslow J, Williams JD, Guy CA, et al: Identification and analysis of the promoter region of the human hyaluronan synthase 2 gene. $J$ Biol Chem 2004;279:20576-20581. 